\title{
Correction to: Is health-related quality of life of patients after single-use flexible ureteroscopy superior to extracorporeal shock wave lithotripsy? A randomised prospective study
}

\author{
Jan Svihra Jr. ${ }^{1,2}$ (1) $\cdot$ Igor Sopilko ${ }^{1}$. Viera Svihrova ${ }^{3}$ - Vladimir Student $^{2}$. Jan Luptak ${ }^{1,4}$
}

Published online: 5 January 2021

○) Springer-Verlag GmbH Germany, part of Springer Nature 2020

\section{Correction to: Urolithiasis \\ https://doi.org/10.1007/s00240-020-01224-4}

The original version of this article unfortunately contained a mistake. Given name and family name were changed. The correct given name and family name are given below.

Jan Svihra Jr. · Igor Sopilko · Viera Svihrova · Vladimir Student · Jan Luptak

The original article has been corrected.

Publisher's Note Springer Nature remains neutral with regard to jurisdictional claims in published maps and institutional affiliations.

The original article can be found online at https://doi.org/10.1007/ s00240-020-01224-4.

Viera Svihrova

viera.svihrova@uniba.sk

1 Clinic of Urology, University Hospital Martin, Kollarova 2, 03659 Martin, Slovakia

2 Urology Clinic of the Faculty Hospital Olomouc, Faculty of Medicine and Dentistry, Palacký University Olomouc, Hněvotínská 3, 77515 Olomouc, Czech Republic

3 Department of Public Health, Jessenius Faculty of Medicine in Martin, Comenius University Bratislava, Mala Hora 11149/4B, 03601 Martin, Slovakia

4 Clinic of Urology, Jessenius Faculty of Medicine in Martin, Comenius University Bratislava, Mala Hora 4A, 03601 Martin, Slovakia 